Proceedings, Intersociety for Energy Conversion Engineering Conference to be held in Honolulu, Hawaii on July 27-August 1, 1997.

$$
\begin{gathered}
A N L / C H M / C P-92375 \\
\text { CONF-970701-- } 97365
\end{gathered}
$$

\title{
A THEORETICAL STUDY OF A CARBON LATTICE SYSTEM FOR LITHIUM INTERCALATED CARBON ANODES
}

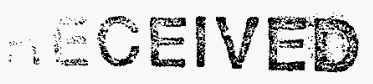

J!I! 211997 OSTI

\author{
${ }^{\star}$ Lawrence G. Scanlon, Donn M. Storch, James H. Newton \\ Aero Propulsion and Power Directorate, Wright Laboratory \\ Wright-Patterson Air Force Base, Ohio 45433-7251 \\ Phone (937)255-7770; Fax (937)656-7529
}

\author{
and \\ *Giselle Sandi \\ Argonne National Laboratory \\ 9700 South Cass Avenue \\ Argonne, Illinois 60439-4831 \\ Phone (630)252-1903; Fax (630)252-9288
}

\begin{abstract}
A theoretical study was performed using computational chemistry to describe the intermolecular forces between graphite layers as well as spacing and conformation. It was found that electron correlation and a diffuse basis set were important for this calculation. In addition, the high reactivity of edge sites in lithium intercalated carbon anodes was also investigated. In this case, the reactive sites appear to strongly correlate with the relative distribution of the total atomic spin densities as well as total atomic charges. The spacing of graphite layers and lithium ion separation within an "approximated" lithium intercalated carbon anode was also investigated. The spacing of the carbon layers used in this investigation agrees most closely for that found in disordered carbon lattices.
\end{abstract}

\section{INTRODUCTION}

Lithium intercalated carbon anodes are very prominent in rechargeable batteries. The nature of the carbon lattice can have great influence on the reversible lithium capacity as well as the decomposition process occurring during lithium intercalation. Since the microstructure of the lattice plays an important role in these processes, it was decided through the use of computational chemistry to investigate the relationship between structure and reactivity for these processes. As a way of bench marking these calculations, the graphite layer spacing in highly ordered graphite and its staggered conformation were used as criteria. Although this calculation is not the prime focus of the invertigation, intermolecular forces between aromatic molecules were calculated. These forces are important for formation of supramolecular structures. The 24 carbon atom molecule coronene was used as a model for the lithium intercalated carbon anode in an attempt to understand the difference in reactivity between edge sites versus basal plane sites during solid electrolyte interphase formation. In particular, the coronene-anion radical was used for this investigation. Understanding the nature of lithium bonding in lithium intercalated carbons is very important for attempting to maximize the lithium reversible capacity. In this regard, the likely hood of anionradical formation in layered structures was investigated.

\section{EXPERIMENTAL}

Gaussian 94 was used for all theoretical calculations (Frisch, et al., 1995). To describe the carbon lattice separation in highly ordered graphite it was found that factoring in electron correlation was necessary. Density functional theory and Moller-Plesset Perturbation theory were used in this regard. The B3LYP method from density functional theory and MP2 method from Moller-Plesset theory were used. Since the nature of this calculation is rather resource intensive, and very time consuming, benzene was used to model the lattice separation and staggered conformation. Calculations of larger molecular systems such as naphthalene and anthracene are now in progress. The $6-31 G(d)$ and $6-31+G(d, p)$ basis sets were used for these calculations.

The 24 carbon atom coronene molecule was used to investigate the distribution of total atomic spin densities through the formation of the coronene-anion radical. The spin restricted Hartree-Fock method of calculation was used in this case. Geometry optimization was achieved at the $6-31 \mathrm{G}(\mathrm{d})$ level. Optimization using the diffuse basis set 6$31+G(d, p)$ is still in progress.

The investigation of the nature of bonding of lithium in lithium intercalated carbon anodes was conducted by comparing and contrasting the behavior of lithium-ions bonded to anion-radicals of molecular systems such as anthracene as well as layered structures. In these examples the spin restricted and unrestricted Hartree-Fock methods were used. Scheme I illustrates the method for calculating the thermodynamic parameters used in this study.

\section{RESULTS AND DISCUSSION}

\section{Highly-Ordered Graphite Approximation}

The results of the ab initio calculations for approximating the highlyordered graphite lattice by two benzene molecules are shown in Table 1. The carbon lattice separation in highly ordered graphite of $3.35 \AA$ is most closely approximated by the Moller-Plesset theory with the 


\section{DISCLAIMER}

This report was prepared as an account of work sponsored by an agency of the United States Government. Neither the United States Government nor any agency thereof, nor any of their employees, makes any warranty, express or implied, or assumes any legal liability or responsibility for the accuracy, completeness, or usefulness of any information, apparatus, product, or process disclosed, or represents that its use would not infringe privately owned rights. Reference herein to any specific commercial product, process, or service by trade name, trademark, manufacturer, or otherwise does not necessarily constitute or imply its endorsement, recommendation, or favoring by the United States Government or any agency thereof. The views and opinions of authors expressed herein do not necessarily state or reflect those of the United States Government or any agency thereof. 


\section{DISCLAIMIER}

Portions of this docement may be illegible in electronic image prodnets. Images are produced from the best arailable original docomentert. 
diffuse basis set where the calculated separation is $3.43 \AA$. One can note the importance of the basis set as to its influence on conformation. Use of the diffuse basis set $6-31+G(d, p)$ results in a staggered conformation which is known to be the case for highly ordered graphite. The calculation based on the 6-31G(d) basis set results in an eclipsed configuration with a lattice separation of $3.73 \AA$. Figure 1 shows the layered carbon lattice approximated by two benzene molecules calculated by RMP2(Full)/6-31+G(d,p).

Moller-Plesset theory was used to calculate the intermolecular forces between the aromatic benzene rings. A value of $6.2 \mathrm{kcal} / \mathrm{mole}$ was obtained using the diffuse basis set. The strength of this interaction was obtained by calculating the energy difference between the bisbenzene system and 2 moles of benzene calculated by the same method and basis set. Use of the $6-31 \mathrm{G}$ (d) basis set results in a calculated intermolecular force of $2.2 \mathrm{kcal} / \mathrm{mole}$.

Calculations based upon density functional theory did not result in very good correlation with the highly-ordered graphite system. Both the lattice separation and configuration were off. In addition the calculated intermolecular force based upon the energy difference of products minus reactants suggest that there is no force of attraction between the aromatic rings since the energy content of the reactants ( 2 benzene molecules at infinite separation) is greater than the product (bisbenzene).

\section{Edge Site Reactivity}

Peled (1966) has discussed the relative reactivity behavior of edge sites versus basal plane sites with respect to solid electrolyte interphase formation during lithium intercalation of graphite anodes. The edge sites are more reactive than the basal plane sites. The edge sites can be further subdivided into zigzag sites and armchair sites. The zigzag sites are more reactive than the armchair sites. In addition, the composition of the solid-electrolyte interphase is different and thicker on the edge sites versus the basal plane sites.

Figure 2 shows the optimized geometry of the 24-carbon atom coronene-anion radical and the numbering scheme for this system associated with the calculated results. The prominent zigzag sites are located at $9,15,23$, and 28 . The armchair sites are located at 1,2,26, and 30 . The numerical values of the total atomic spin densities give an indication of where the free-radical most likely resides. It is interesting to note that the highest values of the total atomic spin densities occur at the zigzag sites as shown in Table 2 . In addition the highest negative charge on the carbon atoms is located at the zigzag sites. The charge on the carbon atoms located at the armchair sites is slightly less than that on the zigzag sites.

If one views the basal plane site as comprised of atoms $7,10,12,14$, 16 and 21 then the distinguishing feature of this site versus the edge sites is the very small amount of negative charge at this site. If the 24carbon atom coronene anion-radical is representative of the carbon lattice used for lithium intercalation anodes, perhaps these differences at the edge sites versus the basal plane sites account for the relative reactivity difference as well as the different composition of the solid electrolyte interphase at these sites. The importance of the negative charge at the edge sites could be construed with a lithium-ion assisted solvent decomposition reaction mechanism.

\section{Layered Structures}

The discussion so far has focused on the carbon lattice. In this part of the discussion the nature of the lithium bonding to a carbon lattice under cathodic conditions will be discussed. To approximate this condition, the general reaction has been investigated whereby a lithium atom in the gas phase [ $\mathrm{Li}^{\circ}$ ] reacts with an aromatic molecule such as benzene or anthracene in the gas phase to yield a product which is either a lithium atom aromatic molecule adduct [i.e., $\mathrm{Li}^{0}$-benzene adduct], or a lithium-ion aromatic molecule anion radical (AR) [i.e., $\mathrm{Li}^{+}$-anthracene-AR]. Table 3 shows the calculated thermodynamic parameters associated with these products. The last three products shown at the bottom of Table 3 have layered structures. Figures 3 and 4 illustrate this class of product. Also shown in this Table are lithiumion-aromatic molecular complexes. The discussion will start with this class of products since there is experimental data to compare with the calculated results.

Staley and Beauchamp (1975) have determined the enthalpies of formation of lithium-ion complexes in the gas phase. The value for the lithium-ion benzene complex is $-37 \mathrm{kcal} / \mathrm{mol} \pm 2 \mathrm{kcal} / \mathrm{mol}$. The calculated enthalpy of formation for this complex using the procedure outlined in scheme 1 is $\Delta \mathrm{H}^{298}=-34.0 \mathrm{kcal} / \mathrm{mol}$. Thus where one is investigating the nature of the lithium-ion bonding to an aromatic molecule the calculations appear to give reasonable results. The enthalpy of formation for the lithium-ion anthracene complex is $\Delta \mathrm{H}^{298}=-38.6 \mathrm{kcal} / \mathrm{mol}$.

During lithium intercalation the carbon anode attains a golden luster color which is attributed to the transfer of electrons to the carbon lattice. It has been found in this investigation that the electron-transfer process and the thermodynamic feasibility of it are very much dependent on the composition and structure of the aromatic lattice. If one considers the reaction of lithium with benzene in the gas phase, there is no electron-transfer to the benzene ring. Instead, a $\mathrm{Li}^{\circ}$ benzene (adduct) is formed where the lithium atom is centered over the benzene ring at a distance of $2.69 \AA$. The total atomic spin density for lithium in this adduct is 0.986 which suggests that the "potential" free-radical electron still residues on lithium. The calculated Gibbs energy change associated with this reaction is $\Delta G^{298}$ $=+6.1 \mathrm{kcal} / \mathrm{mol}$. If one considers the reaction of lithium with anthracene in the gas phase, there is an electron transfer from lithium to anthracene resulting in a lithium-ion-anthracene-anion-radical product. The free-radical predominately residues in the center ring of anthracene. The lithium-ion is centered over this ring at a distance of $1.69 \AA$. The $\Delta E^{\circ}$ for this reaction is $+4.70 \mathrm{kcal} / \mathrm{mol}$. This would tentatively suggest that the electron transfer is not thermodynamically allowed.

If now one considers a layered structure, the thermodynamic feasibility of an electron transfer to the lattice is increased, but it still also depends on the chemical composition of the lattice. If one considers the reaction of lithium with two moles of benzene in the gas phase, the reaction product $\left[\mathrm{Li}^{+}\right.$-(benzene)(benzene-AR)] now has an anion-radical on one of the benzene rings. In this product the aromatic rings are in the eclipsed conformation with a ring separation distance of $4.12 \AA$. It has been found that the aromatic ring separation for a lithium ion bonded to either two benzene molecules or two anthracene molecules is $4.25 \AA$ and $4.18 \AA$, respectively. In the case of the dibenzene system the rings are exlipsed but with the dianthracene system the rings are staggered. The $\Delta \mathrm{E}^{0}$ for the $\left[\mathrm{Li}^{+}\right.$. (benzene)(benzene-AR)] system is $\div 12.6 \mathrm{kcal} / \mathrm{mol}$ and the $\mathrm{Li}^{+}$-anion radical distance is $1.73 \AA$. Even though this process is most likely not thermodynamicaly allowed. the significant change in behavior of this reaction versus when one mole of benzene reacts with lithium is the formation of the benzene-anion radical. An interesting viewpoint in this regard is that the effect of the electron density from the $\pi$-orbital on benzene is to destabilize the highest occupied molecular orbital on the lithium atom and therefore promote the electron-transfer to the 
lowest unoccupied orbital on benzene. If now one considers the layered structures as shown in Figures 3 and 4 the thermodynamic feasibility of the electron-transfer process is considerably enhanced. For the $\left[\mathrm{Li}^{+}\right.$-(anthracene-AR)(benzene)] system the ring-ring separation is $4.08 A$ and the radical is formed on the center ring of the anthracene. In this case the lithium-ion-anthracene-AR distance is $1.82 \AA$. The lithium ion-benzene separation is $2.26 \AA$. In the bis $(\mathrm{Li}$-anthracene-AR) system the charge and multiplicity is 0 and 3 with formation of an anion-radical on each ring. The ring-ring separation is $4.15 \AA$ when measured above/below the end rings where lithium is located but it's $4.22 \AA$ between the center rings. The total atomic spin densities at the center rings show that there is still a high probability of finding the free radical electron at these positions. This may account for the larger ring-ring separation at the center rings. The lithium-ion separation is $5.41 \AA$.

The calculated $\Delta E^{0}$ for these systems are: $\Delta E^{0}=-6.0 \mathrm{kcal} / \mathrm{mol}, \mathrm{Li}$. (anthracene-AR)(benzene)]; and $\Delta E^{0}=-29.3 \mathrm{kcal} / \mathrm{mol}$, [bis $\left(\mathrm{Li}^{*}\right.$ anthracene-AR)]. These calculated results suggest that the electron transfer process would be thermodynamically allowed and therefore consistent with the lithium intercalation process.

The graphite layer separation in stage one lithium intercalated graphite is $3.74 \AA$ (Song, et al., 1996 ). For lithium intercalation in a disordered carbon lattice, the graphite layer separation is approximately $4.0 \AA$ (Sato, et al., 1994). Therefore the layered structures used in these calculations might be more representative of a disordered carbon lattice.

\section{SUMMARY AND CONCLUSION}

A reasonable representation of the separation and conformation of a highly-ordered graphite lattice can be obtained when ab initio calculations are accomplished with a diffuse basis set and electron correlation. Moller-Plesset perturbation theory using MP2 was found to be more satisfactory than Density Functional Theory using B3L.YP. The calculated lattice separation using two benzene molecules as an approximation for the graphite lattice was found to be $3.43 \AA$. The diffuse basis set was important for reproducing the staggered conformation.

The preferred sites for the solid electrolyte interphase (SEI) formation during lithium intercalation are the edge sites versus the basal plane sites. Calculations whereby the carbon-lattice is represented by a 24 carbon atom coronene molecule show that the highest probability of finding the free-radical electron is at the zigzagedge sites. This coupled with a very high negative charge at the edge sites may account for the observed preference of SEI formation at these sites versus the basal plane sites. The importance of the negative charge could be construed with a lithium-ion assisted solvent decomposition reaction mechanism.

The electron-transfer process to the carbon lattice during lithium intercalation of carbon anodes may be dependent upon the fact that the carbon lattice is a layered structure. Ab initio calculations whereby anion-radical formation involved a layered-structure reaction product had a very high $\Delta E^{\circ}$ of $-29.2 \mathrm{kcal} / \mathrm{mole}$. This was the case for the bis $\left(\mathrm{Li}^{+}\right.$-anthracene-AR) system. Without the layered structure for the cases considered, electron-transfer from a lithium atom in the gas phase to an aromatic molecule in the gas phase was not thermodynamically allowed.

\section{ACKNOWLEDGMENTS}

The authors express their gratitude to Marlin Marcum and Casimir Suchyta for the computer support, to Mike Bruggeman for the computer graphics support, and Allen Tumer and Dr. Theresa Windus for review of the manuscript and valuable discussions. Special thanks to Jodie Organisciak for preparation of this manuscript. Work at Argonne was performed under the auspices of the Office of Basic Energy Sciences, Division of Chemical Sciences, U.S. Department of Energy, under contract number W-31-109-ENG-38.

\section{REFERENCES}

Gaussian 94, Revision D.4,

Frisch, M.J., Trucks, G.W., Schlegel, H.P., Gill, P.M.W., Johnson, B.G., Robb, M.A., Cheeseman, J.R., Keith, T., Petersson, GA, Montgomery, J.A., Raghavachari, K., Al-Laham, M.A., Zakrzewski, V.G., Ortiz, J.V., Foresman, J.B., Cioslowski, J., Stefanov, B.B., Nanayakkara, A., Challacombe, M., Peng, C.Y., Ayala, P.Y., Chen, W., Wong, M.W., Andres, J. L., Replogle, E.S., Gomperts, R., Martin, R.L., Fox, D.J., Binkley, J.S., Defress, D.J., Baker, J., Stewart, J.P., Head-Gordon, M., Gonzales, C., and Pople, J.A., Gaussian, Inc., Pittsburgh PA, 1995.

Peled, E. 1996, Private Communication

Sato, K., Noguchi, M., Demachi, A., Oki, N., and Endo, M., 1994, Science 264:556

Song, X.Y., Kinoshita, K., and Tran, T.D., 1996, J. Electrochem. Soc., 143:L120

Staley, R.H., and Beauchamp, J.L., 1975, J. Am. Chem. Soc., 97:5920

\section{Scheme I} $\Delta E^{208}=\Delta E_{i}^{e}+\Delta E_{v}^{0}+\left[\Delta\left(\Delta E_{v}\right)^{20 x}+\Delta E_{r}^{204}+\Delta E_{2}^{298}\right] \equiv$ Thermal Energy
$\Delta H^{298}=\Delta E^{208}+\Delta(P V)$

$\Delta G^{28 x}=\Delta H^{208}-T \Delta S$

\section{Definition of Terms}

$\Delta \mathrm{E}_{\mathrm{s}}{ }^{\circ} \quad$ Electronic energy difference between products and reactants at $0 \mathrm{~K}$.

$\Delta \mathrm{E}_{\mathrm{v}}{ }^{0} \quad$ Difference between the zero-point vibrational energies of the products and reactants $(0 \mathrm{~K})$.

$\Delta\left(\Delta E_{v}\right)^{298}$ Change in the vibrational energy differencebetween $0 \mathrm{~K}$ and $298 \mathrm{~K}$.

$\Delta \mathrm{E}_{\mathrm{r}}^{298}$ Difference in the rotational energies of products and reactants at $298 \mathrm{~K}$.

$\Delta \mathrm{E}_{\mathrm{l}}^{298}$ Difference in the transitional energy change between products and reactants at $298 \mathrm{~K}$.

$\Delta(\mathrm{PV}) \mathrm{PV}$ work term $=\Delta \mathrm{nRT}$ where $\Delta \mathrm{n}$ is equal to the difference in moles between products and reactants. 
TABLE 1. HIGHLY ORDERED GRAPHITE LATTICE APPROXIMATED BY TWO BENZENE MOLECULES

\begin{tabular}{|c|c|c|c|c|}
\hline Molecule & Method/ Bads Set & $\begin{array}{c}\mathbf{E}^{\bullet} \\
\text { (Hartrees)* }\end{array}$ & $\begin{array}{c}\text { Lattice Separation } A \\
\text { Conformation }\end{array}$ & $\begin{array}{c}\text { Calculated Intermolecule } \\
\text { Force keal/mol }\end{array}$ \\
\hline Benzene & RB3LYP/6-31G(d) & -232.2486574 & & \\
\hline Benaene & RB3LYP/6-31+G(d,p) & -232.2683968 & & \\
\hline Bhabemzene & RB3LYP/6-31G(d) & -464.4957778 & 4.20/eclipsed & - \\
\hline Bisbenzene & RB3LYP/6-31+G(d,p) & -464.5363777 & 5.19/eclipsed & - \\
\hline Benzene & RMP2(Full)/6-31G(d) & -231.4871881 & & \\
\hline Benzene & RMP2(Full) $/ 6-31+G(d, p)$ & -231.5501691 & & \\
\hline Błsberrzene & RMP2(Full)/6-31G(d) & -462.9778711 & 3.73/eclipsed & 2.2 \\
\hline Bisbenzene & RMP2(Full) $6-31+G(d, p)$ & -463.1101819 & 3.43/staggered & 6.2 \\
\hline
\end{tabular}

*1 Hartree $=627.5095 \mathrm{kcal} / \mathrm{mole}$

TABLE 2. TOTAL ATOMIC SPIN DENSITIES AND TOTAL ATOMIC CHARGES FOR THE 24 CARBON ATOM CORONENE-ANION RADICAL

\begin{tabular}{|c|c|c|c|}
\hline \multicolumn{3}{|c|}{ Total Atomic Spin Densities } & Total Atomic Charges \\
\hline 1 & $\mathrm{c}$ & .017442 & -.205741 \\
\hline 2 & c & .017076 & -.205357 \\
\hline 3 & C & .073348 & .010826 \\
\hline 4 & $\mathrm{H}$ & .000000 & .160859 \\
\hline 5 & c & .025988 & -.215241 \\
\hline 6 & C & .073922 & .010279 \\
\hline 7 & C & .034696 & -.049006 \\
\hline 8 & $\mathrm{H}$ & .000000 & .160887 \\
\hline 9 & c & .096982 & -.275777 \\
\hline 10 & C & .034876 & -.048901 \\
\hline 11 & $\mathrm{c}$ & .025577 & -.214784 \\
\hline 12 & C & .000797 & -.059227 \\
\hline 13 & $\mathrm{H}$ & .000000 & .157794 \\
\hline 14 & C & .000797 & -.059227 \\
\hline 15 & c & .096944 & -.275721 \\
\hline 16 & c & .034887 & -.048911 \\
\hline 17 & c & .002323 & .086335 \\
\hline 18 & $\mathrm{H}$ & .000000 & .152476 \\
\hline 19 & $\mathrm{H}$ & .000000 & .157832 \\
\hline 20 & C & .073929 & .010291 \\
\hline 21 & C & .034700 & -.049005 \\
\hline 22 & C & .002323 & .086330 \\
\hline 23 & c & .096968 & -.275733 \\
\hline 24 & H & .000000 & .152483 \\
\hline 25 & C & .025583 & -.214790 \\
\hline 26 & C & .017075 & -.205355 \\
\hline 27 & C & .073350 & .010824 \\
\hline 28 & C & .096985 & -.275784 \\
\hline 29. & $\mathrm{H}$ & .000000 & .152480 \\
\hline 30 & C & .017442 & -.205739 \\
\hline 31 & C & .025988 & .215239 \\
\hline 32 & H & .000000 & .157830 \\
\hline 33 & $\mathrm{H}$ & .000000 & .160887 \\
\hline 34 & H & .000000 & .152475 \\
\hline 35 & $\mathrm{H}$ & .000000 & .160858 \\
\hline 36 & H & .000000 & .157794 \\
\hline
\end{tabular}

Sum of Mulliken spin densities $=1.000$ Sum of Mulliken charges $=-1.000$ 
TABLE 3. THERMODYNAMIC PARAMETER FOR AROMATIC MOLECULES AND THEIR LITHIUM COMPLEXES

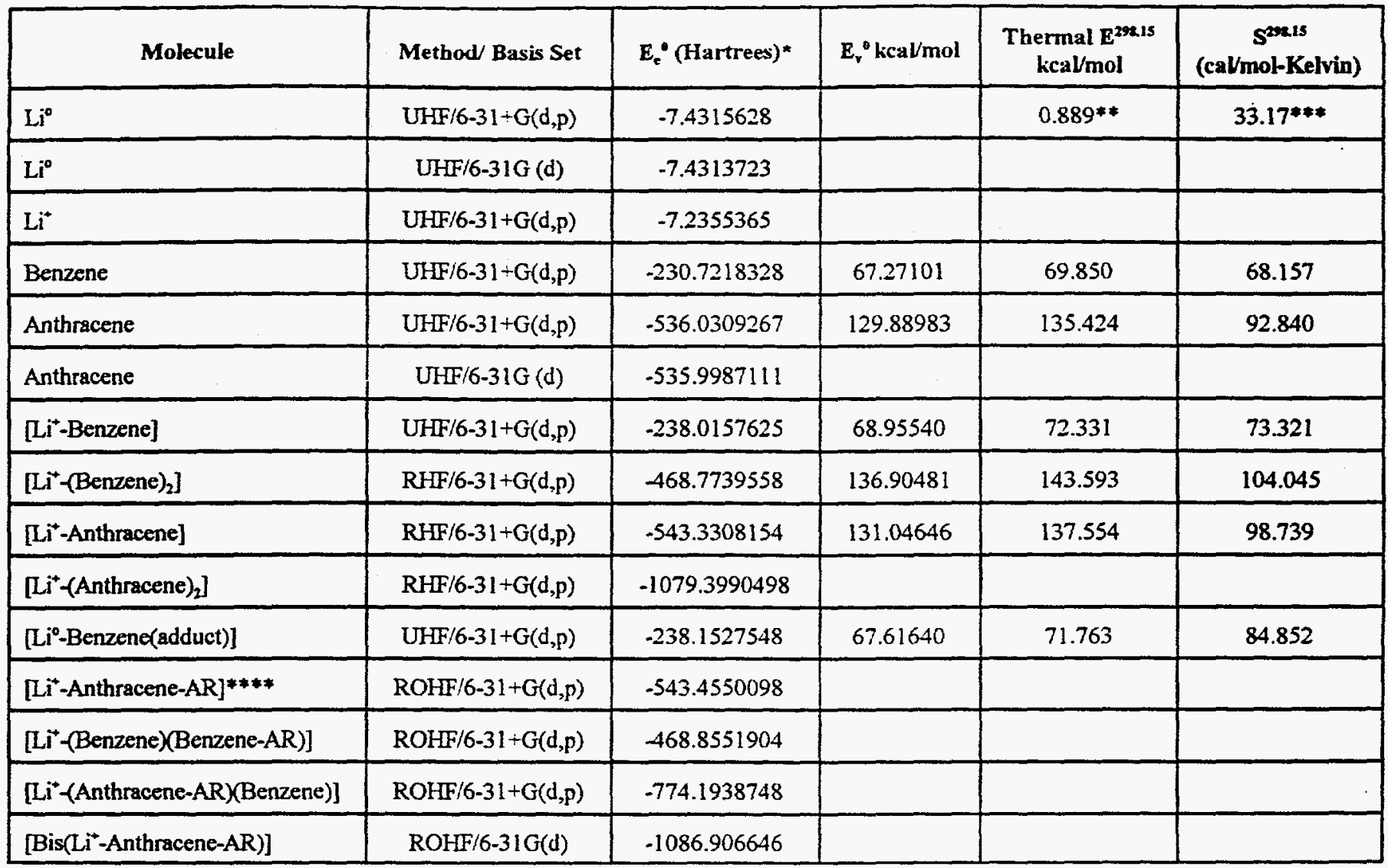

* 1 Hartree $=627.5095 \mathrm{kcal} / \mathrm{mole}$

**Translational term, 3/2 RT

***Experimental Gas Phase Value CRC Handbook of Chemistry \& Physics 73rd Edition ****AR=Anion Radical
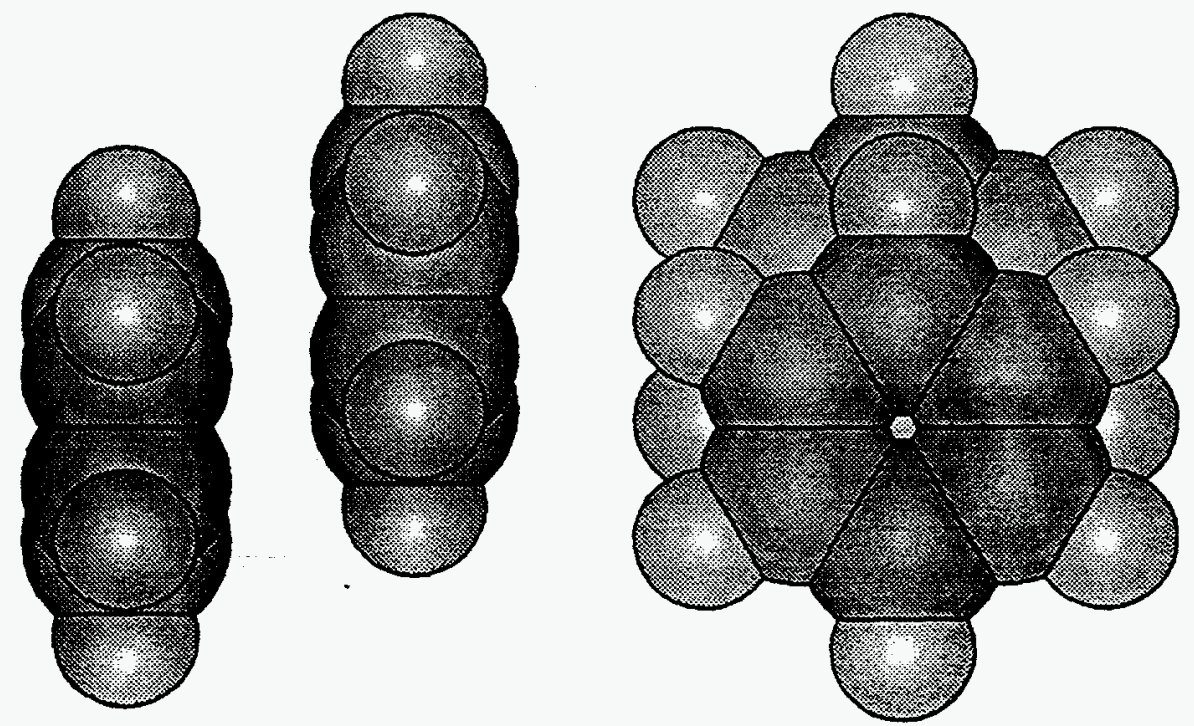

FIGURE 1. HIGHLY ORDERED GRAPHITE LATTICE APPROXIMATED BY TWO BENZENE MOLECULES 


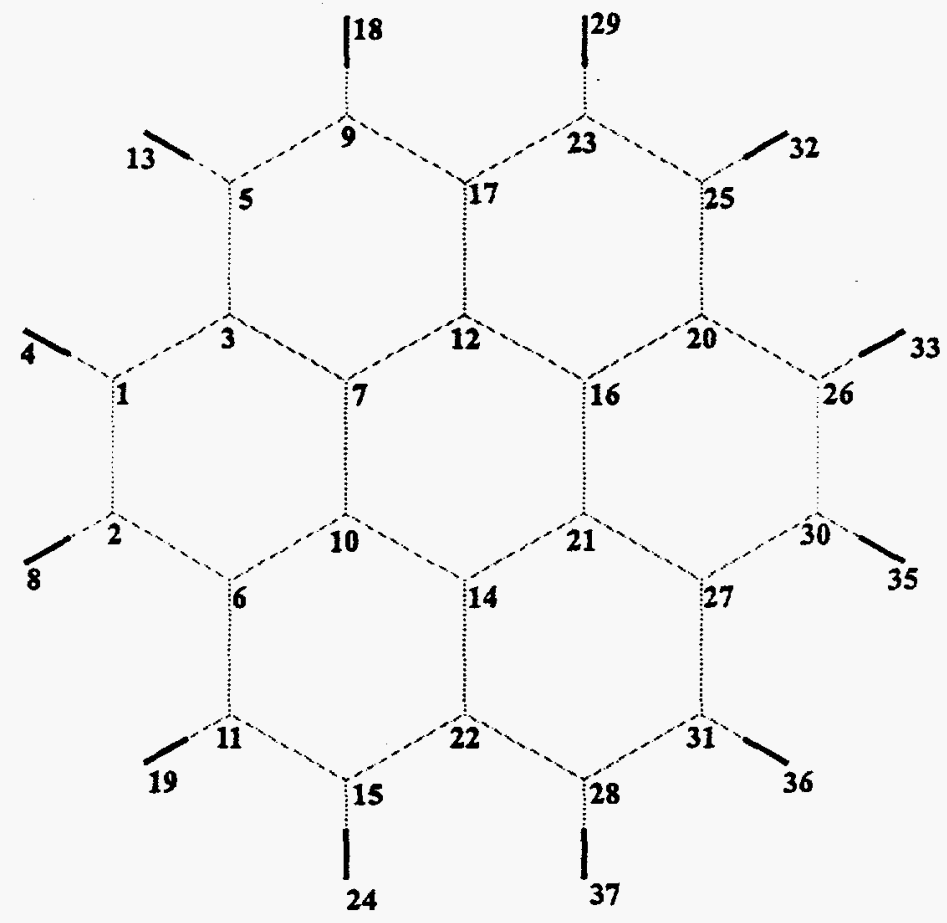

FIGURE 2. OPTIMIZED GEOMETRY OF THE 24-CARBON ATOM CORONENE-ANIONRADICAL

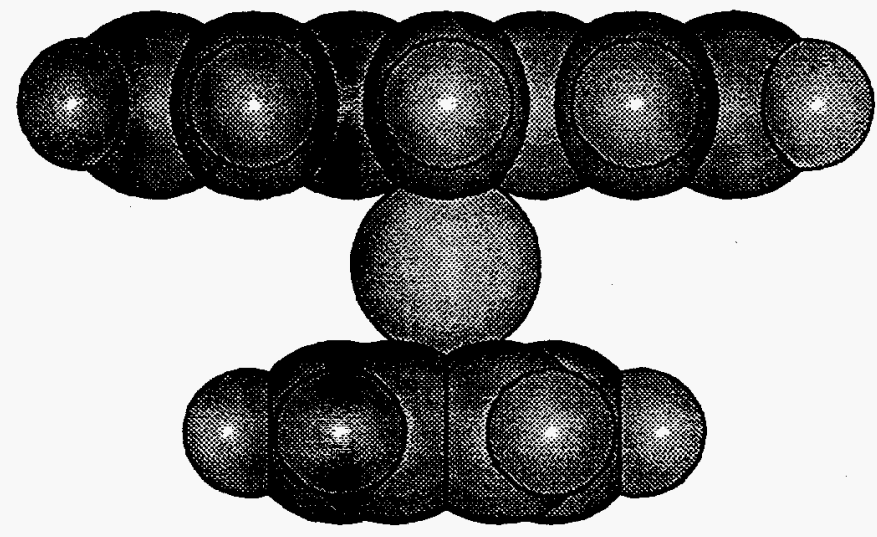

FIGURE 3. OPTIMIZED GEOMETRY OF [L+-(ANTHRACENE-AR) (BENZENE)]

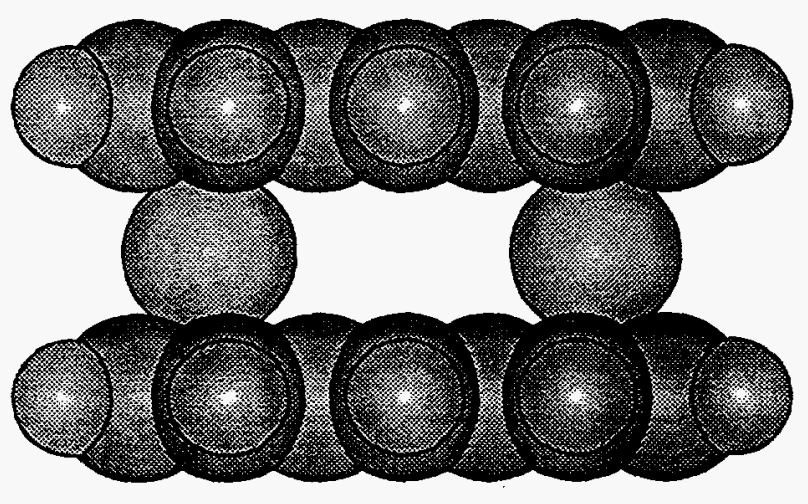

FIGURE 4. OPTIMIZED GEOMETRY OF [BIS $\left(\mathrm{Li}^{+}\right.$-(ANTHRACENE-AR)] 